九州大学学術情報リポジトリ

Kyushu University Institutional Repository

\title{
Applications of Passive Sampling Techniques in Monitoring Organic Pollutants in the Environment
}

\section{Phong, Thai Khanh}

Postdoctoral Research Fellow, National Centre for Environmental Toxicology (Entox), University of Queensland

Phuc, Dam Hoang

Hanoi University of Science and Technology

Tuan, Le Anh

Hanoi University of Science and Technology

Phi, Thai Ha

University of Transport and Communications, Hanoi

他

https://doi.org/10.5109/22068

出版情報: 九州大学大学院農学研究院紀要. 57 (1)，pp.169-174，2012-02. Faculty of Agriculture， Kyushu University

バージョン :

権利関係 : 


\title{
Applications of Passive Sampling Techniques in Monitoring Organic Pollutants in the Environment
}

\author{
Thai Khanh PHONG ${ }^{*}$, Dam Hoang PHUC ${ }^{2}$, Le Anh TUAN ${ }^{2}$, \\ Thai Ha PHI ${ }^{3}$ and Kazuaki HIRAMATSU
}

\author{
Laboratory of Water Environment Engineering, Division of Bioproduction Environmental Sciences, \\ Department of Agro-environmental Sciences, Faculty of Agriculture, \\ Kyushu University, Fukuoka 812-8581, Japan \\ (Received October 31, 2011 and accepted November 9, 2011)
}

\begin{abstract}
As there are a myriad of micro organic pollutants that can affect the well-being of human and other organisms in the environment the need for an effective monitoring tool is eminent. Passive sampling techniques, which have been developed over the last decades, could provide several advantages to the conventional sampling methods including simpler sampling devices, more cost-effective sampling campaign, providing time-integrated load as well as representative average of concentrations of pollutants in the environment. Those techniques have been applied to monitor many pollutants caused by agricultural activities, i.e. residues of pesticides, veterinary drugs and so on. Several types of passive samplers are commercially available and their uses are widely accepted. However, not many applications of those techniques have been found in Japan, especially in the field of agricultural environment. This paper aims to introduce the field of passive sampling and then to describe some applications of passive sampling techniques in environmental monitoring studies related to the agriculture industry.
\end{abstract}

Key words: agricultural activities, environmental monitoring, passive sampling, water quality

\section{INTRODUCTION}

In order to protect the quality of the environment, more and more resources have been invested in environmental monitoring and management. However, the conventional method of environmental monitoring using spot/grab samples faces several difficulties in obtaining representative samples from the monitored environmental compartments. The grab samples only indicate the state of the environment at a particular time and space. While it may be suitable for monitoring an environmental compartment in steady state, the information obtained from grab samples is less representative for actual environmental bodies which are usually in transient state. Passive sampling can overcome such shortcoming by continuously capturing the pollutants in the sampled environment and providing a time-weight average concentration over the sampling (deploying) period (Kot-Wasit et al., 2007).

Thanks to its simplicity, cost-effectiveness and more representative information, passive sampling has become an alternative tool for researchers in environmental monitoring including the many monitoring studies in agricultural areas. Authorities in many countries are now accepting the results of passive samplers for air quality monitoring (Zabiegala et al., 2010) meanwhile more researches are focused on improving the reliability of passive samplers in the aqueous environment so that it can serve for the regulatory purposes.

Postdoctoral Research Fellow, National Centre for Environmental Toxicology (Entox), University of Queensland, Australia

${ }^{2}$ Hanoi University of Science and Technology, Vietnam

University of Transport and Communications, Hanoi, Vietnam

* Corresponding author (E-mail: p.thai@uq.edu.au)
However, the application of passive sampling in Japan is still very limited, especially in the area of environmental monitoring for agriculture-originated pollutants such as pesticides, veterinary drugs... More frequent use of passive samplers in these fields will help reduce cost and labor while will produce more representative data. Therefore, this paper aims to:

- Briefly review the current state of passive sampling in the world and the situation of environmental monitoring using passive samplers in Japan

- Description of some monitoring activities using passive samplers in agricultural areas that have the potential to be applied in Japan

\section{CURRENT STATE OF PASSIVE SAMPLING}

\section{Principles of passive sampling}

Passive sampling is based on the free flow of targeted compounds' molecules from the sample matrix to the receiving phase. The difference in concentrations between the sampled environment and the passive sampler will transform into potential gradients of the targeted compounds between the two media which in turn will result in enrichment and isolation of the compounds into the receiving phase (Fig. 1). However, the mass transfer of pollutants from the environment into the samplers is reversible which is critical for the next step of sample extraction and analysis.

Passive samplers are usually prepared in the laboratory (or provided by manufacturers). At the sampling site, they are exposed to the monitored environment. After a certain period of time depending on the type of samplers and the targeted pollutants the samplers are retrieved for extraction and measurement. Because the treatment of samples collected either using passive sam- 


\section{Surrounding environment}

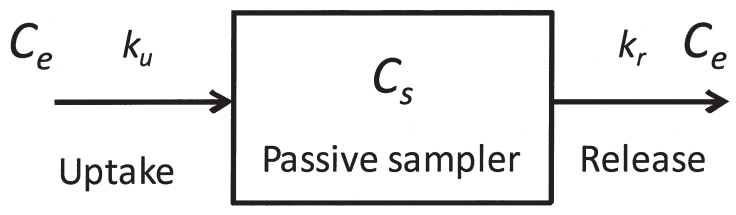

Fig. 1. Single compartment model for the concept of passive sampling, $C_{e} . C_{s}$ are the concentrations of pollutants in the environment and the passive sampler, $k_{u}$ and $k_{r}$ are the uptake and release rate of the pollutants from the passive sampler.

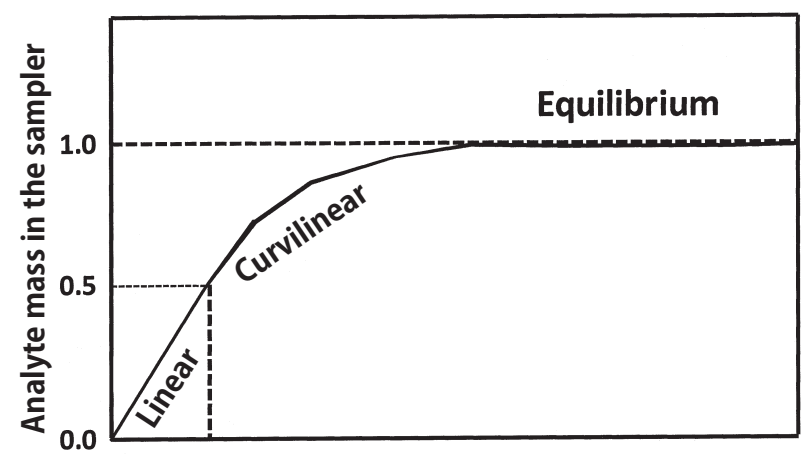

Time

Fig. 2. Uptake curve for a passive sampler showing 3 stages of pollutant accumulation.

pling or conventional sampling is not remarkably different, the passive sampling is aimed mainly to address the issues of simplicity and cost-effective in environmental sampling.

The basic and popular theory of passive sampling can be expressed graphically as in Fig. 2. It means that the accumulation (or sampling) of pollutants to the samplers is assumed to follow first-order kinetics. During the first stage, the chemicals are accumulated linearly relative to time. Then as the gradient of chemical concentrations decreases, the sampling moves into the curvilinear stage and then move to the equilibrium stage when there is no gradient between the 2 media.

In order to use passive samplers to measure concentrations of pollutants in the environment, it is a prerequisite to calibrate the samplers for the range of pollutants they are going to measure. Calibration parameters include sampling rates, partition coefficients and loss rate constants. The calibration parameters are usually determined in the laboratory, at a reference site or in situ (Bartkow et al., 2005). For quantification purposes, the passive samplers are expected to be in the linear accumulation stage with known sampling rate (obtained from the calibration process) during the deployment in the field (sampling period).

\section{Application of passive samplers}

The last two decades have seen the application of passive sampling techniques in different areas, including workplace exposure and monitoring. indoor and outdoor air-quality determination, aquatic sampling for ground and surface water pollution, and sediment and soil pollution monitoring (Zabiegała et al., 2010). However, as the matrix becomes more and more complicated from air to water and to sediment/soil, more research is required before passive sampling can be applied routinely in the latter compartments.

1) Passive sampling for air quality monitoring

From their early development in the seventies for measuring volatile organic chemicals using linear uptake kinetics (Huckins et al., 2006a) passive sampling technology has now been widely accepted in the field of air quality monitoring as evidenced by many regulatory guidelines, manuals and protocols published by various environmental and standards authorities including the EPA, American Society for Testing and Materials (ASTM), International Organization for Standardization (ISO), etc. (Seethapathy et al., 2008).

There are numerous applications of passive sampling techniques for measurement of pollutants in the atmosphere such as inorganic compounds (IC), volatile organic compounds (VOC), persistent organic pollutants (POPs) and volatile pesticides to obtain information on the relative amounts (concentrations) or patterns (temporal and spatial trends) as well as on regulatory compliance monitoring (Kot-Wasik et al., 2007). However, the main applications for air quality monitoring lie in the field of occupational atmosphere/indoor assessment or of monitoring spatial and temporal distribution of Volatile Organic Compounds or Semi Volatile Organic Compounds (including POPs) in the atmosphere (regional or global). And applications of those techniques to the agriculture is the monitoring of pesticide drift and/or vapor in the areas (especially domestic areas) adjacent to the agricultural fields during pesticide application period (Gil and Sinfort 2005). There are many types of air passive samplers as reviewed by Partyka et al. (Partyka et al., 2007). Fig. 3 shows an example of air passive sampler using Poly Urethane Foam (PUF) to measure the concentration of PAHs and PCBs in the atmosphere.

More details about air passive sampling techniques and their application can be found in a review by Partyka et al. (Partyka et al., 2007) and various book chapters (Bartkow et al., 2007; Chen and Pawliszyn 2007; Gioia et al., 2007; Anna-Lena 2007; Zabiegała and Namieśnik 2007; Popp et al., 2007)

2) Passive sampling for water quality monitoring

Passive samplers for aqueous compartment have been developed after the success of air passive samplers and they are still in a stage of intensive validation and improvement. However, those samplers designed for monitoring organic pollutants (pesticides, pharmaceuticals, PAHs, PCBs...) in the water compartment are now receiving the greatest interest from researchers in the field of passive sampling. The reason is that those industrial or agricultural pollutants are contaminating our depleting water supply around the world. Therefore, more stringent management and protection measures have been introduced into regulations in many countries, 

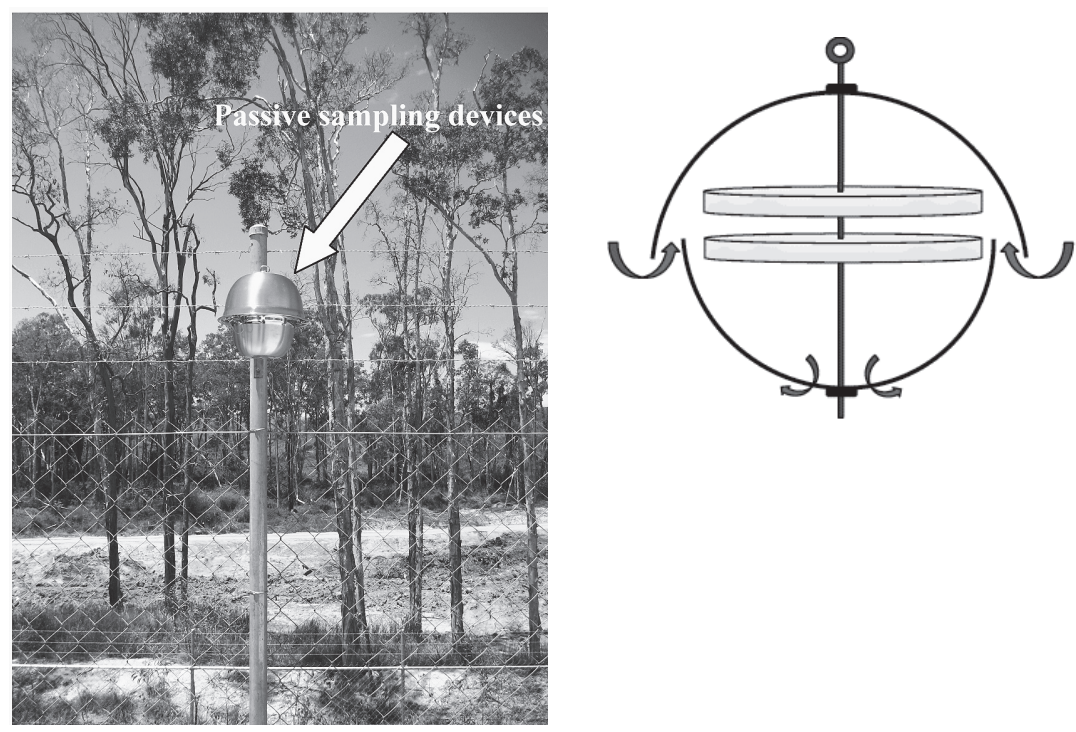

Fig. 3. Example of an air passive sampler deployed in the field (Courtesy of Prof. Jochen Mueller, Entox) and its design.

especially in the European Union (Mills et al., 2009). In order to enforce such regulations, continuous monitoring of water bodies is critical. Passive sampling can play the role of a simple, cost-effective tool for such extensive monitoring programs. Many of those samplers have been used for several years and some are commercially available. Among the most popular passive samplers for aquatic environment are:

- Semi-permeable membrane device (SPMD) for hydrophobic organic pollutants (such as PAHs, organochlorine pesticides, PCBs...). This sampling device is well established and a whole book was devoted to the description of this devices (Huckins et al., 2006a)

- The diffusive gradients in thin films (DGTs) for metals and inorganic ions (such as lead, mercury, asenic...).

- The membrane-enclosed sorptive coating (MESCO), the nonpolar Chemcatcher® for nonpolar organic pollutants similar to the targets of the SPMD

- The polar Chemcatcher®, the polar organic integrative sampler (POCIS), the Empore ${ }^{\mathrm{TM}}$ extraction disks for a range of polar organic chemicals (e.g. some pesticides, pharmaceuticals and personal care products).

Some of those sampling devices are shown in Fig. 4. These samplers have been also compared with living organisms and have been found to provide robust, sensitive models of bioaccumulation, and show potential for routine use in a range of aggressive environments where it would be difficult to deploy living organisms (Mills et al., 2009).

Although widely used in research, these samplers have not yet been accepted by the authorities for their regulatory purposes. It is because before passive sampling can be employed for regulatory practice it is necessary to introduce proper quality assurance and quality

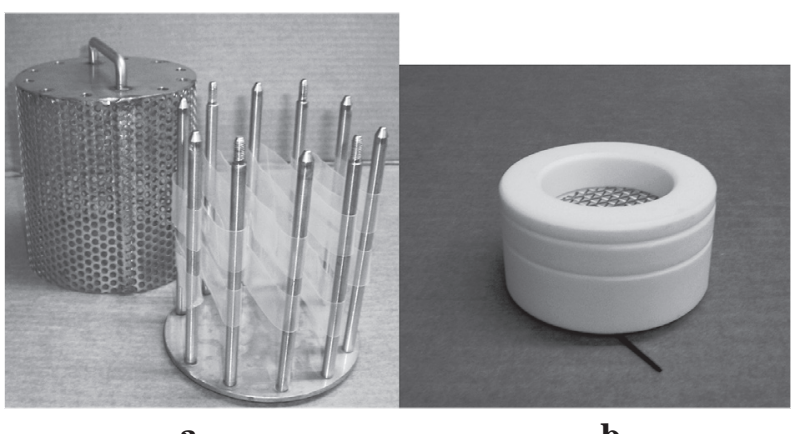

a

b

Fig. 4. Passive sampling devices (a) SPMD cage and (b) Empore Disk (Courtesy of Prof. Jochen Mueller, Entox).

control procedures to ensure the validity of the results. More research is needed to develop appropriate reference materials, and standard methods. One approach that might prove effective would be the use of carefully regulated test sites with artificial stream systems and mesocosms (Mills et al., 2009; Huckins et al., 2006b).

Passive sampling in water compartment can be utilized extensively for monitoring programs of pollutants resulted from agricultural activities (pesticides, veterinary pharmaceuticals), especially when it is required to measure those non-point source pollution in rivers or lakes. Integrative passive samplers have been used to measure the concentrations of pesticides in surface waters (Thomatou et al., 2011; Tran et al., 2007). The expanding range of chemicals that passive sampling technique is capable of measuring will enable extensive monitoring program for pesticides in river water throughout the world.

3) Passive sampling for pollutants in soil/sediment

Compared to passive sampling techniques applied to air and aqueous matrices, the application of passive sampling to soil/ sediment compartment has a relatively short history (Seethapathy et al., 2008). Most applications of 
passive sampling in soil/sediment in the literature have been reported recently. However, the heterogeneity of soil/sediment matrix compared to those of air and water makes the use of passive sampling an advantage because it can reduce considerably the cost of any sampling campaign for the spatial distribution of chemicals in soil/sediment.

Main chemicals of interest for passive sampling from soil/sediment are metals and VOCs/SVOCs (such as chlorinated, aliphatic and aromatic compounds). It would be beneficial to use passive samplers as the simulation models of plants for chemical uptake study in agricultural science as the behavior of those samplers are quite similar to that of some plants. The main shortcoming of soil/ sediment passive samplers is that most of their applications are restricted to qualitative or screening purposes only (Seethapathy et al., 2008). Much more research is required until passive sampling technique in soil/sediment can reach the level of those in air and water.

\section{PASSIVE SAMPLING IN JAPAN}

\section{General situation}

Passive sampling has been used in Japan for quite a long time. However, the number of researches applying this technique is still very limited. A search from Web of Knowledge ${ }^{\circledR}$, with the keyword of "passive sampling" and "Japan" only resulted in 30 publications reporting the use of passive sampling until now. In Japan, the technique was initially used for measuring concentrations of gases in the atmosphere in epidemiological studies. Yanagisawa et al. (1986) reported the use of filter-badge type samplers to measure the concentrations of $\mathrm{NO}_{2}$ in a personal exposure study in Tokyo (Yanagisawa et al., 1986). The applications were later expanded to other gases and volatile organic compounds in the atmosphere with focus on the organic halogen compounds (Yamada et al., 1999; Olansandan et al., 1999; Amagai et al., 1999).

In recent years, the range of pollutants covered by passive samplers in Japan has been increasing. Emerging pollutants such as polychlorinated biphenyls, organochlorine compounds, and polybrominated diphenyl ethers, polyfluorinated compounds have been tackled in air monitoring campaigns (Jaward et al., 2005; Oono et al., 2008; Shinohara et al., 2010; Takigami et al., 2009) while the imminent risk of formaldehyde led to more passive sampling techniques to measure this volatile chemical (Shinohara et al., 2007; Endo et al., 2001; Maruo et al., 2010). Research on pollutants in aquatic environment was also initiated, tackling metal ions (Aung et al., 2008). Although most of the effort now is concentrated on air monitoring, the advantage of passive sampling technique in wide range environmental monitoring cannot be neglected in future research in Japan.

\section{Passive sampling technique for agricultural pollut- ants in Japan}

The risk of pollutants from agricultural activities is significant, especially in Japan where the regulation has been relatively soft until recently. Several monitoring studies have indicated the problem of river water contamination due to pesticides used in paddy field in Japan (Tanabe et al., 2001; Son et al., 2006; Phong et al., 2010). However, there is no report in the literature about the application of passive sampling technique for monitoring pesticides in Japanese rivers while all the basin-scale monitoring studies have been conducted by spot/grab sampling with a frequency of weekly or even monthly. The missing information between 2 sampling point couldn't be interpreted and it reduced the quality of the dataset. For a better/more representative monitoring result, it is recommended to apply passive samplers as a complementary method of monitoring pesticides in river water so that no peak or cave of pesticide concentration $\mathrm{s}$ in the monitoring sites will be missed.

\section{EXAMPLES OF USING PASSIVE SAMPLING TECHNIQUES TO MONITOR POLLUTANTS ORIGINATED FROM AGRICULTURAL ACTIVITIES}

The most eminent pollutants originated from agricultural activities in Japan are pesticides, especially pesticides used in rice paddy fields due to their frequent runoff/drainage events from the field to the open water stream (Phong et al., 2010). Therefore, the following examples will focus on the successful use of passive samplers to measure pesticide concentrations in the water compartment as evidence for the potential of applying those samplers in Japan.

\section{Calibration of passive samplers for pesticides from rice producing area}

In a short report, Hyne and Aistrope (2006) have described the calibration of three passive sampling devices using different materials as sampling absorbents. After laboratory calibrations against a range of pesticides used in rice fields, all three passive samplers were tested again conventional sampling method (continuous daily composite sampling) in canal of large rice field area.

The results of the field study indicated that average concentrations produced by all passive samplers were comparable (within 2-fold) of the concentrations of daily composite samples. The study also indicated that unless passive samplers or continuous sampling devices are used, it is easy to miss the peak of the targeted pesticides in the canal.

The pesticides monitored in this study are simazine, bromacil, thiobencarb, molinate, diuron, fipronil, metolachlor, atrazine, clomazone, endosulfan, which are popular with most of them also being used in Japan, especially thiobencarb. Therefore, there are potential of using these passive samplers for the monitoring of rice pesticides in water stream in Japan.

\section{Monitoring pesticides in coastal water of the Great Barrier Reef}

The Great Barrier Reef (GBR) is a natural world heritage in the North of Queensland, Australia. The inshore area of the GBR is place of intensive agricultural activi- 
ties including sugarcane and cattle grazing. Therefore, pesticide runoff from agriculture poses a threat to water quality and thus to the survival of the GBR. Shaw et al. (2010) described the application and evaluation of passive samplers as tools for broad-scale monitoring in the GBR environment. An extensive survey of pesticides was conducted with samplers deployed at river mouth and nearshore Reef sites in the Wet Tropics in both a dry and wet season and in a cross-shelf transect from river source to the outer Reef.

Three popular types of passive samplers, namely Chemcatcher ${ }^{\circledR}$ with Empore disk as sorbent phase, SPMD and polydimethylsiloxane (PDMS), were used to capture both polar and non-polar pesticides in the water. Several pesticides were detected in both polar and nonpolar samplers. Those accumulated in polar samplers and detected were diuron, atrazine, simazine, hexazinone, chlorpyrifos and prothiophos. Pesticides detected by non-polar samplers were metolachlor, diazinon, propiconazol, fipronil, chlorpyrifos, pendimethalin, chlorfenvinphos. The detection of those pesticides confirmed the risk of agricultural runoff to the biodiversity of the GBR although the mass of pesticide accumulated on each sampler was at the level of ng, indicating the high sensitivity of passive sampling technique. The highest concentration of detected in river waters in this study was that of diuron (350 ng $\mathrm{L}^{-1}$ ), much lower than the level usually found in Japan river of $\mu \mathrm{g} \mathrm{L}^{-1}$. In addition, the simplicity of the passive samplers has enabled the deployment of samplers throughout transect of about two hundred kilometers in offshore area of the GBR considering that the researchers had to travel by boat to some sampling points. It is again an evidence for the potential of passive sampling in monitoring pesticide contamination in water that can be utilized in Japan.

\section{DISCUSSION AND CONCLUSION}

Despite many advances in passive sampling techniques around the world, the application of those techniques in Japan is still limited. Currently, most of the applications in Japan reported in the literature are in the field of air quality and domestic/occupational exposure to gases and volatile/semi volatile organic compounds where internationally standardized protocols exist. There is a great potential to apply those techniques to monitor the pesticides and pharmaceuticals used in agriculture. Advantages compared to the conventional method of grab sampling include:

1. Continuous sampling at the monitoring point to capture the load or time-weight average concentrations of pollutants in the stream.

2. Reducing labor cost for high frequency sampling campaign.

3. Enabling more extensive monitoring campaign by deploying the samplers in remote areas without the need of power and security for usual sampling devices.

4. Easy to archive the samples (less spaces and fragility compared to storing liters of water in glass bottles).

With the tightening of the regulation on environmental quality standards in Japan including lower allowable concentrations of pollutants in water, stricter management practice (Katayama, personal communication), more extensive monitoring campaigns are required to ensure appropriate data for the enforcement of the standards. As passive sampling has been proved to possess several advantages in environmental monitoring compared to the conventional sampling technique, it is considered suitable for use in year-round monitoring of pesticides and probably pharmaceuticals which are used in high volume in agriculture (rice cultivation, cattle, swine industries...). More applications of passive sampling technique in Japan would lead to a better understanding of the contamination situation in the environment.

\section{REFERENCES}

Amagai, T., Olansandan, H. Matsushita, M. Ono, S. Nakai, K. Tamura and K. Maeda 1999 A survey of indoor pollution by volatile organohalogen compounds in Katsushika, Tokyo, Japan. Indoor and Built Environment 8: 255-268

Anna-Lena, S. 2007 Comprehensive Analytical Chemistry vol. 48. R. Greenwood, G. M. and Vrana, B. eds. Elsevier pp. 57-83

Aung, N. N., F. Nakajima and H. Furumai 2008 Trace metal speciation during dry and wet weather flows in the Tama River, Japan, by using diffusive gradients in thin films DGT. Journal of Environmental Monitoring 10: 219-230

Bartkow, M. E., C. E. Orazio, T. Gouin, J. N. Huckins, and J. F. Müller 2007 Comprehensive Analytical Chemistry vol. 48 R. Greenwood, G. M. and Vrana, B. eds. Elsevier pp. 125-137

Chen, Y. and J. Pawliszyn 2007 Comprehensive Analytical Chemistry vol. 48. R. Greenwood, G. M. and Vrana, B. eds. Elsevier pp. 3-32

Endo, Y., T. Miyazaki, Y. Hikita, M. Azuma, H. Ikeda, K. Fukunaga and G. Endo 2001 Sampling methods and residential factors affecting formaldehyde concentration in indoor air. Tohoku Journal of Experimental Medicine 195: 227-236

Gil, Y. and C. Sinfort, 2005 Emission of pesticides to the air during sprayer application: A bibliographic review. Atmospheric Environment, 39: 5183-5193

Gioia, R., K. C. Jones and T. Harner 2007 Comprehensive Analytical Chemistry vol. 48. R. Greenwood, G. M. and Vrana, B. eds. Elsevier pp. 33-56

Jaward, F. M., G. Zhang, J. J. Nam, A. J. Sweetman, J. P. Obbard, Y. Kobara and K. C. Jones 2005 Passive air sampling of polychlorinated biphenyls, organochlorine compounds, and polybrominated diphenyl ethers across Asia. Environmental Science \& Technology 39: 8638-8645

Kot-Wasik, A., B. Zabiegała, M. Urbanowicz, E. Dominiak, A. Wasik, and J. Namieśnik 2007 Advances in passive sampling in environmental studies. Analytica Chimica Acta, 602: 141-163

Huckins, J. N., Booij, K. and Petty, J. D. 2006a, Monitors of Organic Chemicals in the Environment, Springer US pp. $1-28$

Huckins, J. N., K. Booij, and J. D. Petty 2006b Monitors of Organic Chemicals in the Environment, Springer US pp. 139-167

Hyne R. and M. Aistrope 2006 Continuous sampling of pesticides in waterways. IREC Farmers' Newsletter 171: 21-23

Maruo, Y. Y., T. Yamada, J. Nakamura, K. Izumi and M. Uchiyama 2010 Formaldehyde measurements in residential indoor air using a developed sensor element in the Kanto area of Japan. Indoor Air 20: 486-493

Mills, G. A., Vrana, B. and Greenwood, R. 2009 Rapid Chemical and Biological Techniques for Water Monitoring John Wiley \& Sons, Ltd pp. 53-69 
Olansandan, T. Amagai and H. Matsushita 1999 A passive sampler-GC/ECD method for analyzing 18 volatile organohalogen compounds in indoor and outdoor air and its application to a survey on indoor pollution in Shizuoka, Japan. Talanta 50: 851-863

Oono, S., K. H. Harada, M. A. M. Mahmoud, K. Inoue and A. Koizumi 2008 Current levels of airborne polyfluorinated telomers in Japan. Chemosphere 73: 932-937

Partyka, M., B., Zabiegała, J. Namiésnik, and A. Przyjazny 2007 Application of Passive Samplers in Monitoring of Organic Constituents of Air. Critical Reviews in Analytical Chemistry, 37: 51-78

Phong, T., K. Yoshino, K. Hiramatsu, M. Harada and T. Inoue 2010 Pesticide discharge and water management in a paddy catchment in Japan. Paddy and Water Environment 84: 361-369

Popp, P., H. Paschke, B. Vrana, L. Wennrich and A. Paschke 2007 Comprehensive Analytical Chemistry vol. 48. R. Greenwood, G. M. and Vrana, B. eds. Elsevier pp. 107-123

Seethapathy, S., T. Górecki and Li, X. 2008 Passive sampling in environmental analysis. Jourmal of Chromatography A, 1184: 234-253

Shaw, M., M. J. Furnas, K. Fabricius, D. Haynes, S. Carter, G. Eaglesham and J. F. Mueller 2010 Monitoring pesticides in the Great Barrier Reef. Marine Pollution Bulletin 60: 113122

Shinohara, N., M. Fujii, A. Yamasaki and Y. Yanagisawa 2007 Passive flux sampler for measurement of formaldehyde emission rates. Atmospheric Environment 41: 4018-4028

Shinohara, N., T. Kataoka, K. Takamine, M. Butsugan, H. Nishijima and M. Gamo 2010 Modified Perfluorocarbon Tracer Method for Measuring Effective Multizone Air Exchange Rates. International Journal of Environmental Research and
Public Health 79: 3348-3358

Son, H. V., S. Ishihara and H. Watanabe 2006 Exposure risk assessment and evaluation of the best management practice for controlling pesticide runoff from paddy fields. Part 1: Paddy watershed monitoring. Pest Management Science 62: 1193-1206

Takigami, H., G. Suzuki, Y. Hirai, Y. Ishikawa, M. Sunami, and S. I. Sakai, 2009 Flame retardants in indoor dust and air of a hotel in Japan. Environment International 35: 688-693

Tanabe, A., H. Mitobe, K. Kawata, A. Yasuhara and T. Shibamoto 2001 Seasonal and spatial studies on pesticide residues in surface waters of the Shinano River in Japan. Journal of Agricultural and Food Chemistry 49: 3847-3852

Thomatou, A.-A., I. Zacharias, D. Hela, and I. Konstantinou 2011 Passive sampling of selected pesticides in aquatic environment using polar organic chemical integrative samplers. Environmental Science and Pollution Research 187: 1222 1233

Tran, A. T. K., R. V. Hyne and P. Doble 2007 Calibration of a passive sampling device for time-integrated sampling of hydrophilic herbicides in aquatic environments. Environmental Toxicology and Chemistry 26: 435-443

Yamada, E., M. Kimura, K. Tomozawa and Y. Fuse 1999 Simple analysis of atmospheric $\mathrm{NO}_{2}, \mathrm{SO}_{2}$, and $\mathrm{O}_{3}^{-}$in mountains by using passive samplers. Environmental Science \& Technology $\mathbf{3 3}$ $4141-4145$

Yanagisawa, Y., H. Nishimura, H. Matsuki, F. Osaka, and H. Kasuga 1986 Personal exposure and health effect relationship for $\mathrm{NO}_{2}$ with urinary hydroxyproline to creatinine ratio as indicator. Archives of Environmental Health 41: 41-48

Zabiegała, B. and J. Namieśnik 2007 Comprehensive Analytical Chemistry vol. 48. R. Greenwood, G.M. and Vrana, B. eds. Elsevier pp. 85-106 